\title{
Pulmonary Function Test of Forced Vital Capacity and Slow Vital Capacity Using Spirometry in Young Adults With Respect to Body Mass Index: A Normative Study
}

\author{
Jyothy Anthraper \\ PG student, Department of Speech Language \\ Pathology and Audiology \\ Naseema Institute of Speech and Hearing Bangalore, \\ Karnataka, India-560047
}

Abstract

$>$ Objectives:

To determine the effect of Age, Gender and its correlation on pulmonary functions of Forced Vital Capacity and Slow Vital Capacity in Group I (18-24 years) and Group II (25-30 years) with respect to Body Mass Index.

\section{$>$ Methodology:}

Sixty healthy adults between 18-30 years were included in the study. Participants were subdivided into Group I (18 to 24 years) and Group II (25 to 30 years) each group having 15 males and 15 females. The parameters considered were expiratory reserve volume, tidal volume, inspiratory capacity, forced vital capacity and slow vital capacity. Spirometer RMS HELIOS 401 was used. Procedures were explained to each participant; best values from 3 maneuvers were documented and were subjected to analysis.

\section{$>$ Results:}

It is noticed a significant difference in various parameters of pulmonary function. As age increases there was an increase in body mass index and the lung volume also increased. Overall males had higher pulmonary function compared to females, males in Group II (25-30 years) was better compared to males in Group I (18-24 years). With an increase in body mass index, pulmonary function was increased in males compared to females. Age, gender, age, and gender interaction effect with respect to Body Mass Index was seen.

\footnotetext{
$>$ Conclusion:

Values obtained can be used as reference standard for estimation of lung volume for age group 18-30 years. In future, Spirometry can be used as a clinical assessment and management tool in the field of speech language pathology, by modifying respiratory patterns to control lung volumes, phonations and the flow of speech.
}

\author{
Dr. Reeny Roy \\ Associate Professor, Department of Speech Language \\ Pathology and Audiology \\ Naseema Institute of Speech and Hearing Bangalore, \\ Karnataka, India-560047
}

Keywords:- Forced Vital Capacity, Pulmonary function, Spirometry, Slow Vital Capacity, young healthy adults.

\section{INTRODUCRTION}

Speech, a form of human communication, is produced by three groups of organs working together: respiratory, phonatory and articulatory. The dominant elements of the respiratory system are the lungs, the chest wall, and the diaphragm. Working together, they provide the mechanical energy in form of air pressure, the aerodynamic energy of the speech needed to produce sound in the larynx [1].

The respiratory function testing using spirometry has gained momentum as a clinical measure and is presently considered as an essential prerequisite to diagnose various obstructive and restrictive disorders of the respiratory system. It involves measuring changes in air volume, air flow and pressure which indicate respiratory function. These measures help in determining the important aspects of lung function. Aerodynamic measures are useful in the clinical assessment of airway obstruction and voicing.

Speech language pathologists usually consider vital capacity as a sole measure in the evaluation of respiratory function. Pulmonary ventilation is the act of breathing, which can be described as the movement of air into and out of the lungs. The major mechanisms that drive pulmonary ventilation are atmospheric pressure (Patm); the air pressure within the alveoli, called alveolar pressure ( $P$ alv); and the pressure within the pleural cavity, called intrapleural pressure (Pip). The alveolar and intrapleural pressures are dependent on certain physical features of the lung. However, the ability to breathe - to have air enter the lungs during inspiration and air leave the lungs during expiration is dependent on the air pressure of the atmosphere and the air pressure within the lungs. The difference in pressures drives pulmonary ventilation because air flows down a pressure gradient, that is, air flows from an area of higher pressure to an area of lower pressure. 
The breath requirements for speech production are not quite different from those required for life purposes. Approximately 50 percent of vital capacity is inhaled for speech purposes, it concludes that if the breathing behaviour of the individual is within normal broad limits and is sufficiently deep for life purposes, it ought to be perfectly adequate for speech purposes [2]. By comparing children's and adult's respiratory behaviour during speech task found that, at loud intensity, adults used a higher percentage of their vital capacity than the children [3].

\section{$>$ Factors Affecting the Pulmonary Function Test}

The values of pulmonary function tests are usually determined by many factors, such as age, gender, race, geographical region, height and weight with respect to BMI. The total lung volumes and capacities decline when people get older, and the total lung capacities and force expiratory volume are larger in males than females. Additionally, Ethnic differences in lung function have been proved, especially for Asians, Latin Americans, Indians, and South Africans.

It is believed that norms specific to different languages and race should be established when evaluating the performance of phonatory aerodynamic measurements [4]. Studies [5] showed that an age- dependent increase in the airflow rate during phonation. women and boys have airways that are smaller relative to lung size than are those of men and that these sex differences develop late in the growth period [6]. There are two major changes to the pulmonary system associated with aging. These changes are decreased elastic recoil and stiffening of the chest wall [7]. Elastic recoil on the lungs depends on the composition of the connective tissue, and alveolar surface tension produced by surfactant [8]. Also, pulmonary functions remain the major biologic variable that is affected by aging. Extent of the ageing process in the lungs shows great interindividual variations [9]. Study conducted amongst elderly Chinese [10] showed age related decline in FVC compared to men. Similar decline with age was obtained in studies conducted on the elderly European males and females; however, the values of FVC obtained in both sexes were higher [11].

For the same height, boys have greater lung function values than girls. Lung function increases linearly with age until the adolescent growth spurt at about age 10 years in girls and 12 in boys [12]. The pulmonary function vs. height relationship shifts with age during adolescence. Thus, a single equation or the pulmonary function-height growth chart alone does not completely describe growth during the complex adolescent period.

Obesity reduces lung compliance leading to airway closure, pulmonary and gas trapping, thereby, an increase in respiratory system elastance is seen. In individuals with a BMI $25 \mathrm{~kg} / \mathrm{m} 2$ who do not have obstruction (defined as FEV1/FVC ratio lower than LLN), FVC is larger than SVC. In contrast, in overweight and obese individuals, SVC is larger than FVC, and the SVC- FVC difference is positively correlated with BMI [13].

\section{METHODOLOGY}

A standard group comparison research design was implied for the study. There were sixty healthy adults' participants in the range of 18 to 30 years. They were subdivided into two groups. The participants were grouped according to age and sex with fifteen males and fifteen females in each of the following age group: Group I (8-24 years), Group II (25-30 years). The objectives of the study was to determine the effect of age and its correlation on the pulmonary function of Forced Vital Capacity and Slow Vital Capacity in Group I (18yr- 24yr) and Group II (25-30 years) with respect to Body Mass Index. Also, to determine the effect of Gender and its correlation on pulmonary functions of Forced Vital Capacity and Slow Vital Capacity with respect to Body Mass Index.

Inclusion criteria was followed for the study which includes no history of laryngeal pathology or voice disorders, neurological, cardiovascular, or other medical disease that could affect speech, Subjects were nonsmokers and non-alcoholics and had normal structural and functional oral peripheral mechanism. The purpose and the procedure of the current study were explained to the Participant verbally. A written consent also obtained from the respective persons.

\section{A. Procedure}

The recordings are carried out in quiet room which was away from the noisy environment no other person or distraction present was in the room. First the general procedure was explained to the participants. They must sit upright holding the hand piece to their mouth and throughout the maneuver the participant should try to keep their back straight as much as possible. The participant should hold the transducer hand unit in such a way that the air passage is completely unobstructed, then the maneuver is performed, each participant was given 3 trials to practice the maneuver and the best of the 3 values from the maneuvers were documented. Before starting the test with the next subject, the mouth tubes are cleaned and sterilized properly.

\section{B. Description about Working of Helios 401}

The Micro Controller is powered through the USB. The pulses that are generated in the transducer by the participants breathe gets amplified by the amplifier and sent to the Micro Controller. The Micro Controller processes data and transfer it to computer which is displayed on computer screen. In the performance of spirometry, the following steps are taken: The transducer is fixed into the transducer assembly. The transducer has an arrow on the surface and is inserted in the direction indicated by the arrow. The transducer will click into position when correctly connected. The mouthpiece is fixed (disposable or reusable) over this assembly and will click into position when correctly connected. The transducer assembly is then connected to the computer using the USB cable. The participant is then trained for test performance. The participant's collaboration is essential to carry out the maneuvers correctly. A nose clip is used to allow air to flow 
only through the participant's mouth. The participant holds the transducer hand unit in such a way that the air passage is completely unobstructed. The participant's hands, fingers, or clothing are ensured it is not obstructing the air flow. The area in front of the participant is also kept clear to avoid back-draft of air entering the turbine and affecting the readouts. The Start icon is pressed and the pre-medication in the dialog box is selected. Finally, the maneuver is performed, and the Stop icon is then clicked. Alternatively, the transducer is kept in place until the device detects the end of the expiratory maneuver according to ATS criteria. This criterion is satisfied when the volume accumulated during the last second is lower than 0.03 litres.

After the maneuver is performed, the display screen will show the graph obtained. The maneuver number will be shown either in the centre column of the screen (FVC) or along the bottom of the screen. After each successive maneuver is performed a dialog box, specific to the type of test, appears. The observed values of the current maneuver and the previous maneuver is compared. Based upon these readings and the action suggested by the software. the user can accept or reject the maneuver. If the maneuver is rejected, then the observations are lost. If the maneuver is accepted, then the readings get stored as a numbered maneuver. Only accepted maneuvers are added to the list of maneuvers performed. Out of the list of accepted maneuvers the user can carry out analysis.

\section{Performing the FVC test}

The general procedure is explained to the participant. When the participant's information is loaded into the database, click FVC, then the test screen is displayed. The participant is asked to begin relaxed tidal breathing through the mouthpiece fixed over the transducer and then to take a deep breath in. Simultaneously the Start button is clicked and the appropriate choice of the test Pre-Medication is made. Immediately after this the participant is asked to blow out as hard and fast as possible and continue blowing until no more air can be exhaled. Then the participant is asked to take another deep breath back in with the mouthpiece still in his mouth, until the lungs are full.

The test is repeated as required until adequate test data was acquired or until a maximum of eight acceptable maneuvers have been performed.

Specific features of FVC, the FVC screen shows space to obtain the Flow/volume and Volume/Time graphics. The current maneuver being displayed is indicated by the blue arrow in the centre column of the semen. For example, maneuver 2 is pointed by the blue arrow.

All maneuvers together can be seen by clicking Show all Maneuvers, located in the centre column of the screen. Thickness of line of curves can be selected by positioning the slider, located at the bottom of the screen to the required level. Maneuvers to be displayed can be selected by checking the appropriate tick boxes at the bottom of the screen.

\section{Performing the SVC test}

The SVC test is a less strenuous method of finding participant's Vital Capacity. Click SVC, then the test screen is displayed. The participant is asked to begin relaxed tidal breathing through the mouthpiece fixed over the transducer. Simultaneously the Start button is clicked and the appropriate choice of the test Pre-Medication is made. Next the participant is asked to take a deep breath followed by a deep exhalation. Both Inhalation and exhalation should be performed to the maximum extent but slowly. After this the participant is asked to take a few gentle and normal breaths. Then the stop button is clicked. The test is repeated until adequate test data has been acquired. or until a maximum of Eight acceptable maneuvers have been performed.

\section{E. Calculation of Body Mass Index}

BMI is calculated for all participants by measuring the weight using a calibrated weighing machine in kilogram. Weight measurements were done by using a calibrated weighing machine. The machine was placed on a flat surface, the participant was asked to step on it with bare feet and to stand still on the weighing machine with both feet even and flat and the measurements were done in kilograms.

Height measurement were done using a measuring tape against the wall. It was done by using a pencil and standing with the back against a wall the pencil is used to mark where the highest point on the top of the head meets the wall. Then the measuring tape is used to measure the distance from the floor to the mark you made on the wall.

The formula used for calculating Body Mass index is $\mathrm{BMI}=$ weight $(\mathrm{kg}) /$ height $^{2}\left(\mathrm{~m}^{2}\right)$

\section{$\mathrm{M}=$ Meters}

\section{F. Data collection}

Values used in this analysis included the vital capacity (VC), forced vital capacity (FVC), slow vital capacity (SVC), Expiratory reserve volume (ERV), Tidal volume (TV), Inspiratory capacity (IC). Vital capacity (VC) is the maximum amount of air a person can expel from the lungs after a maximum inhalation.

A mean (mid) value is used as the reference value when interpreting results but there are upper and lower levels of normal values; lung volumes of $80-120 \%$ of the predicted values are considered to be within normal limits by American thoracic society.

Spirometry software has built-in algorithms that provide an interpretation of the measured data. Most often, these classify the patients into four quadrants based on the pattern of the ventilatory defects. Spirometry allows recognition of patterns of ventilatory impairments that may be produced by different diseases: obstructive pattern, pattern suggestive of restriction, pattern suggestive of a mixed obstructive-cum-restrictive process and, variable and fixed large airway obstruction. This categorization is done 
by examining the flow volume curve and the measured parameters.

In healthy people, around three-quarters of the forced vital capacity (FVC) can be exhaled in the first second. Therefore, the forced expiratory volume in one second (FEV1) should be around three- quarters of the FVC. This gives an FEV1: FVC ratio (FEV1/FVC or FEV1\%) of around 0.75 or $75 \%$. The slope for the normal values rises rapidly to reach its high point before declining and producing a record of the FVC. Fig. 1. shows the ratio between FVC\% and FEV1/FVC\%.

\section{$\mathrm{VC}=\mathrm{IRV}+\mathrm{TV}+\mathrm{ERV}$}

Forced vital capacity (FVC) is the amount of air that can be forcibly exhaled from lungs after taking the deepest breath possible, as measured by spirometry in liters.

Slow vital capacity (SVC) is the volume of air expired through an unforced maneuver

Expiratory reserve volume (ERV) is the amount of extra air above a normal breath exhaled during a forceful breath out. Tidal volume (TV) is the lung volume representing the normal volume of air displaced between normal inhalation and exhalation when extra effort is not applied. Inspiratory capacity (IC) is the volume of air that can be inspired following a normal quite expiration and is equal to tidal volume plus inspiratory reserve volume.

Using this procedure FVC and SVC of all the subjects were recorded on the computer for further analysis. The total time taken to record the FVC and SVC from each patient was 10 to 15 minutes approximately. The data obtained are displayed either as a graph or as a table of values.

\section{G. Graphical representation of spirometry results}

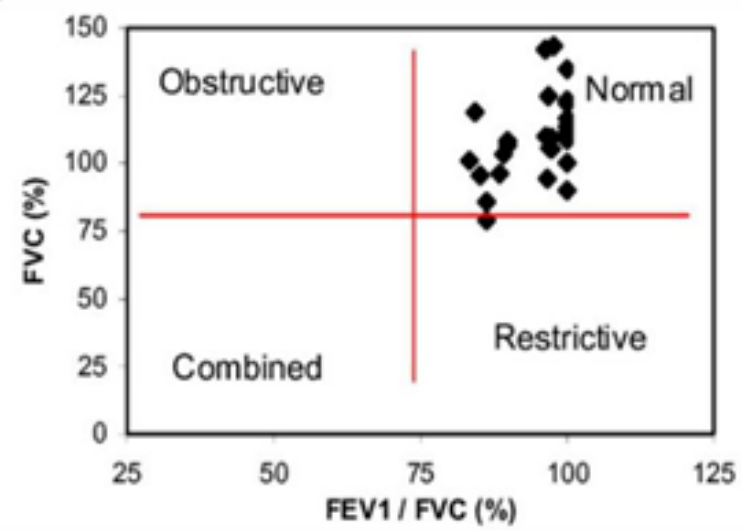

Fig 1:- View of ratio between FVC\% and FEV1/FVC\%. Quadrant (upper left) classified as obstructive, Quadrant (upper right) classified as normal, Quadrant (lower left) classified as combined and quadrant (lower right) classified as restrictive
In obstructive lung disease, whether acute or chronic, will reduce the FEV1 by increasing the airway resistance to expiratory flow. In chronic air flow obstruction, the chronic resistance can lead to chronic hyperinflation of the lungs. Due to premature closing of the airways on expiration, the FVC will also decrease but not as much as the FEV1. The FEV1/FVC will fall. The flow/volume graph has a concave appearance. The volume/time graph depicts a line that rises slowly to reach its highest point, completing the full expiratory maneuver.

When a forced expiration is performed with severely obstructed airways, there may be more collapse of the airways, An FEV1/FVC of $<0.7(70 \%)$ is diagnostic of air flow obstruction and confirms obstructive disease.

However, a lower than normal FEV1/FVC may not be abnormal for an asymptomatic older person. The FEV1 does not have to be $<80 \%$ predicted for a diagnosis of airflow obstruction. If the FEV1 is $\geq 80 \%$ predicted value with an FEV1/FVC of $<0.7 \%$ (70\%), a diagnosis of COPD should only be made in the presence of respiratory symptoms such as breathlessness or cough. Other causes of obstruction include: enlarged thyroid gland (goitre), tumor, inhaled foreign body, Epiglottal closure, Straining of throat area, such as vocal cord dysfunction. Fig. 2. shows the spirometric display of obstructive lung diseases.

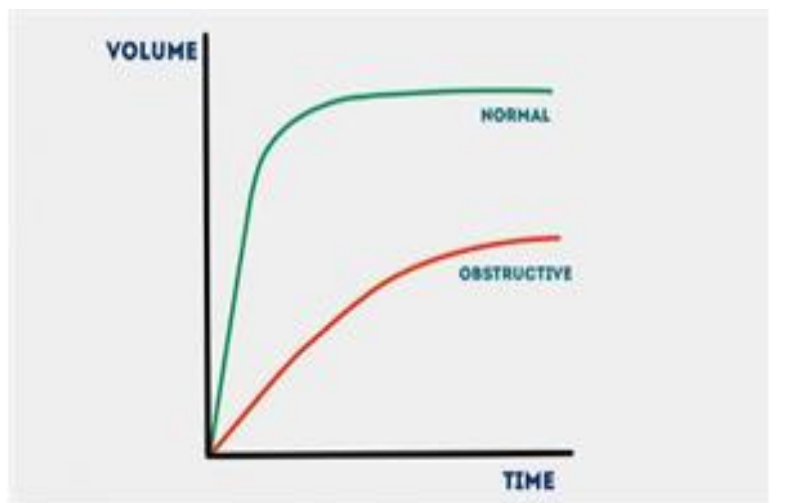

Fig 2:- Display of volume-Time spirogram for normal and obstructive lung diseases

Restrictive lung disease is caused by extrapulmonary conditions affecting movement of the chest wall and intrapulmonary conditions affecting lung elasticity. Both affect inflation of the lungs and cause lung volumes to be reduced, but the calibre of the airways is unaffected. The volume/time graph has a shape like normal, but with a lower FEV1 and a lower FVC. The flow/volume graph has a squashed appearance.

Restrictive disorders have a near-normal or higher than normal FEV1/FVC, but both the FEV1 and FVC are reduced proportionally. Fig. 3. shows the spirometric display of restrictive lung diseases. 


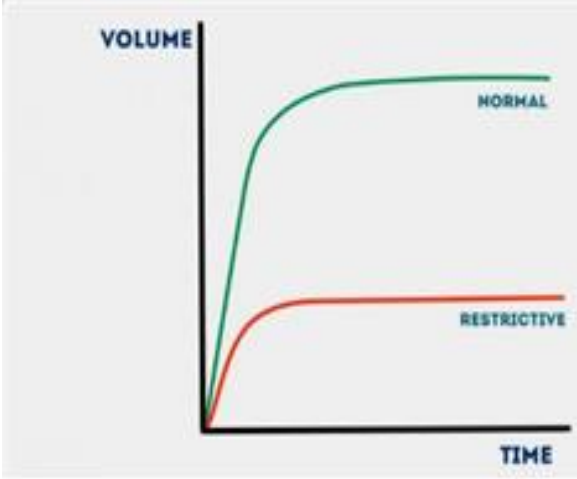

Fig 3:- Display of Volume-Time spirogram for normal and restrictive lung diseases

In mixed obstructive-cum-restrictive lung disease, if a patient has asthma or COPD and develops a significant consolidation, such as pneumonia or a pleural effusion, the results may demonstrate airflow obstruction and some restriction. The patient is likely to be symptomatic.

\section{RESULTS AND DISCUSSION}

Descriptive statistical analysis was carried out to determine the Mean (M) and Standard Deviation (SD) for the pulmonary functions for the age groups, Group I (1824years) and Group II (25-30 years) including males and females. SPSS software. (Statistical Package for the Social Sciences) version 21 was utilized for analysis. Analysis was carried out for pulmonary functions of Expiratory Reserve Volume, Tidal Volume, Inspiratory Capacity, Forced Vital capacity, and Slow Vital Capacity across age group, gender, and Body Mass Index. Values on weight and height of the participants are provided in Appendix B.
The normality assumption was considered by carrying out the Shapiro Wilks tests for normality. The test revealed the data significantly follows normal distribution $(p>0.05)$. Therefore, a parametric test Two-way MANOVA was carried out to see the effect of age groups (18-24, 25-30), gender (male, female) on parameters. Also, the interaction effect of age*gender is observed. Since there is an interaction effect found for many parameters the independent two- sample t-test is carried out to see the gender effect on parameters with respect to age groups and the age effect on parameters with respect to gender is carried out. The Karl Pearson's coefficient of correlation is carried out to see the correlation between BMI and other parameters. All statistical $p$ - values are compared with 0.05 and 0.01 level of significance. The present study provides the following statistical analysis findings for the above objectives.

\section{A. MANOVA analysis}

A parametric test Two-way MANOVA was conducted to find the overall age, gender and age and gender interaction effect by considering all the parameters of pulmonary function.

Table 1 Two-way MANOVA was conducted to find out for the age (18-24 years and 25-30 years), gender (males and females) and age gender interaction effect. In this study the $p$-value for age is 0.00 , for gender is 0.00 and age gender interaction effect is 0.00 , respectively. In this study since the $p$ value is lesser than 0.05 , which means a difference is observed hence the Null hypothesis is rejected, and Alternative Hypothesis is accepted. Therefore age, gender, age, and gender interaction effect are significant in this study.

\begin{tabular}{|c|c|c|c|c|}
\hline Source & df1 & df2 & F & p-value \\
\hline Age Group & 6 & 51 & 961.37 & $\mathbf{0 . 0 0}^{* *}$ \\
\hline Gender & 6 & 51 & 26.85 & $\mathbf{0 . 0 0}^{* *}$ \\
\hline Age Group * Gender & 6 & 51 & 4.20 & $\mathbf{0 . 0 0}^{* *}$ \\
\hline
\end{tabular}

Table 1:- Two-way MANOVA analysis

NOTE: df- degree of freedom, F-ratio of F-test, p- significant value.* Indicates significant at $p<0.05 * *$ Indicates significant at $p<0.01$

\begin{tabular}{|c|c|c|c|}
\hline $\begin{array}{c}\text { Parameters of } \\
\text { Pulmonary } \\
\text { Function }\end{array}$ & Source & F $(\mathbf{1 , 5 6 )}$ & p-value \\
\hline \multirow[t]{3}{*}{ BMI } & Age group & 23.00 & $0.00^{* *}$ \\
\hline & Gender & 4.01 & 0.50 \\
\hline & Age group $*$ Gender & 3.19 & 0.07 \\
\hline \multirow[t]{3}{*}{ ERV } & Age group & 19.64 & $0.00^{* *}$ \\
\hline & Gender & 1.53 & 0.22 \\
\hline & Age group $*$ Gender & 0.03 & 0.86 \\
\hline \multirow[t]{3}{*}{ TV } & Age group & 0.91 & 0.34 \\
\hline & Gender & 13.90 & $0.00^{* *}$ \\
\hline & Age group $*$ Gender & 1.00 & 0.32 \\
\hline \multirow[t]{3}{*}{ IC } & Age group & 0.02 & 0.88 \\
\hline & Gender & 43.12 & $0.00^{* * *}$ \\
\hline & Age group $*$ Gender & 0.98 & 0.32 \\
\hline
\end{tabular}


ISSN No:-2456-2165

\begin{tabular}{|c|c|c|c|}
\hline \multirow{3}{*}{ FVC } & Age group & 9.31 & $\mathbf{0 . 0 0}^{* * *}$ \\
\cline { 2 - 4 } & Gender & 64.96 & $\mathbf{0 . 0 0}^{* * *}$ \\
\cline { 2 - 4 } & Age group * Gender & 0.10 & $\mathbf{0 . 7 4}^{*}$ \\
\hline \multirow{3}{*}{ SVC } & Age group & 19.10 & $\mathbf{0 . 0 0}^{* *}$ \\
& Gender & 84.17 & $\mathbf{0 . 0 0}^{* *}$ \\
\cline { 2 - 4 } & Age group ${ }^{*}$ Gender & 4.43 & $\mathbf{0 . 0 4}^{*}$ \\
\hline
\end{tabular}

Table 2:- MANOVA Analysis is carried out for each of the variables separately with respect to age, gender, age, and gender interaction

NOTE: BMI-Body Mass Index, ERV-expiratory reserve volume, TV- tidal volume, IC-inspiratory capacity, FVC-forced vital capacity, SVC-slow vital capacity, Fratio of $\mathrm{F}$-test, $\mathrm{p}$-significant value $*$ indicates significant at $p<0.05 * *$ indicates significant at $p<0.01$

From table 2 we can see each variable has different effect. With BMI, age group has statistical significance $(p=0.00)$.In this study a difference was observed in BMI between age groups I(18-24 years) and group II(25 to 30 years) However, there was no significant difference shown between gender $(p=0.50)$, age group and gender interaction $(p=0.79)$.

With the parameters of expiratory reserve volume (ERV) there was statistical significance $(p=0.00)$ between age group I (18 -24 years) and group II (25-30 years).

However, there was no significant difference shown between gender $(p=0.22)$, age group and gender interaction $(p=0.86)$.

For parameters such as Tidal volume (TD) there was statistical significance $(p=0.00)$ between gender. However, there was no significant difference $(p=0.34)$, shown between age group I (18-24 years) and age group II (25-30 years), age group and gender interaction $(p=0.32)$
Considering Inspiratory Capacity there was statistical significance $(p=0.00)$ between gender, however, there was no significant difference $(p=0.88)$ shown between age group I (18-24 years) and group II (25-30years), age group and gender interaction $(p=0.32)$

With Forced Vital Capacity (FVC) there was statistical significance $(p=0.00)$ between age group I $(18-24$ years) and age group II (25-30 years), also significant difference $(p=0.00)$ for gender, but no significant difference $(p=0.74)$ between age group and gender interaction.

For Slow Vital Capacity (SVC) there was significant difference $(p=0.00)$ for age group I (18-24 years) and group II ( 25 to 30 years) and between gender (male and female) respectively. But there was no significant difference $(p=0.04)$ between age group and gender interaction effect.

B. To determine the effect of Age on pulmonary functions of FVC and SVC in Group I (18-24 years) and Group II (25-30 year) with respect to Body Mass Index

Table 3 shows the effect of age on the pulmonary functions of FVC and SVC in Group I in 15 males and 15 females in the age range of 18 to 24 years with respect to Body Mass Index.

\begin{tabular}{|c|c|c|c|c|c|}
\hline Parameters of pulmonary function & $\begin{array}{c}\text { Gender } \\
(\mathrm{N}=30)\end{array}$ & Mean & SD & t (28) & p-value \\
\hline \multirow[t]{2}{*}{ ERV } & Male & 1.62 & 0.04 & \multirow[t]{2}{*}{5.91} & \multirow[t]{2}{*}{0.41} \\
\hline & Female & 1.51 & 0.06 & & \\
\hline \multirow[t]{2}{*}{ TV } & Male & 1.57 & 0.61 & \multirow[t]{2}{*}{2.13} & \multirow[t]{2}{*}{$0.02^{*}$} \\
\hline & Female & 1.20 & 0.28 & & \\
\hline \multirow[t]{2}{*}{ IC } & Male & 2.68 & 0.48 & \multirow[t]{2}{*}{4.80} & \multirow[t]{2}{*}{0.62} \\
\hline & Female & 1.89 & 0.40 & & \\
\hline \multirow{2}{*}{ FVC } & Male & 3.74 & 0.22 & \multirow[t]{2}{*}{13.46} & \multirow[t]{2}{*}{0.91} \\
\hline & Female & 2.61 & 0.23 & & \\
\hline \multirow[t]{2}{*}{ SVC } & Male & 3.55 & 0.50 & \multirow[t]{2}{*}{16.62} & \multirow[t]{2}{*}{$0.00^{* *}$} \\
\hline & Female & 1.36 & 0.02 & & \\
\hline
\end{tabular}

Table 3:- Descriptive statistics and t-values for the pulmonary functions of FVC and SVC for age Group I (18 to 24 years) in males and females

NOTE: ERV- expiratory reserve volume, TV- tidal volume, IC-inspiratory capacity, FVC-forced vital capacity, SVC-slow vital capacity, N- number of participants, S.D- standard deviation, t- two-sample t-test, p- significant value* Indicates significant at $p<0.05 * *$ Indicates significant at $p<0.00$ 


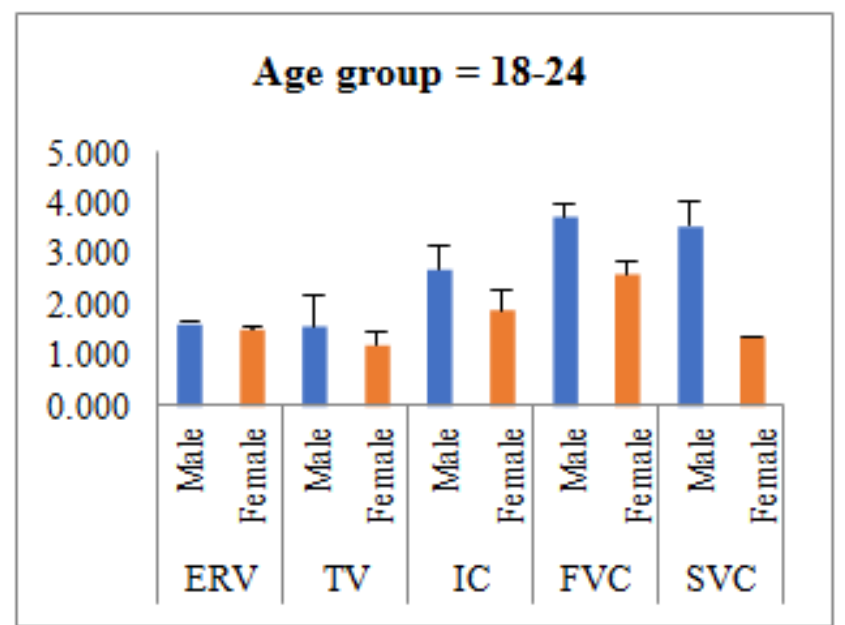

Fig 4:- Represents pulmonary functions for Group I (18-24 years) for males and females

Table 3 and Fig. 4. shows the descriptive statistical analysis of Mean, Standard Deviation, and t- values obtained for the pulmonary functions for the age group 18 to 24 years for 15 males and 15 females. As seen in Table 3 and Fig. 6 the males in the age group of 18 to 24 years had the highest value for $\mathrm{FVC}($ Mean $=3.77, \mathrm{SD}=0.22$ ) followed by SVC, IC, TV and lowest for ERV (Mean=1.62, $\mathrm{SD}=0.04)$. Similarly, the function of FVC (Mean=3.74 SD 13.46) was also the highest for the female group in this age range followed by IC, ERV, SVC and the lowest for TV (Mean 1.20 SD 0.28).

Higher FVC values in males and females in the younger age group of 18 to 24 years indicates, that the participants had no restrictive and obstructive disorders; therefore, they did not alter the volume of airways. This finding is in line with the study by [14] that parameters of respiration reach a maximum value during the younger years of life compared to a decline seen as age progresses in healthy adults. The present findings of our study are also in line with the study by [15] who reported an increase in spirometry and lung volumes from 15 to 25 years.

Overall, on comparison of the pulmonary functions for males and females in the age range of 18 to 24 years, it could be seen from Table 3 and Fig.6 that the values for FVC, SVC, IC, TV and ERV were higher in males compared to females.

As age increases there was an increase in height and all the pulmonary values reached its peak with both age and height in men. In the current study, 12 males were above average height and 5 of them were within the average range in the age group of 18 to 24 years and thus showed a significant correlation with higher values for FVC, TLC, FRC and alveolar volume.
This is in accordance with the findings by [16] men had greater muscle strength (inspiratory and expiratory) than women, which can be due to the force-length relationship of skeletal muscles. As seen in Table 3, statistical parametric analysis of Independent t-test for Group I reveals no significant difference between males and females for ERV $(\mathrm{t}=5.91, \quad p<0.41), \quad$ IC $\quad(\mathrm{t}=4.80, \quad p<0.62)$ and FVC $(\mathrm{t}=13.46, p<0.91)$. However, there was significant difference for $\mathrm{TV}(\mathrm{t}=2.12, p<0.29)$ and SVC $(\mathrm{t}=16.62 p<0.00)$ in males (Mean 2.63, SD=0.37) and females (Mean 1.71, SD=0.19). This could be because female lungs tend to be smaller and weigh less than male, and the total number of alveoli and alveolar surface area is larger for males. This is supported by a similar finding by [17] which showed the effect of the alveolar wall and elastic recoil pressure on pulmonary functions.

The difference was seen in slow vital capacity and tidal volume in the current study in the younger age in determining the pulmonary functions, which is supported by the findings in a study which could be due to the changes in anatomical structures and height. pulmonary functions that are greater than that predicted based on age, suggests body build play a role [18]. The increase in tidal volume and slow vital capacity seen in the younger population can be related to the Flow rate and lung volume for airways, chest size and height. It is also supported by the finding of [19] which explained the increase in tidal volume and slow vital capacity were observed when breathing at a lower percentage of their total lung volume which indicates the importance of physiological changes in the alveolar surface.

Fig. 5. shows the effect of age in Group I (18 to 24 years) with respect to BMI. It could be seen that young male adults had a slightly higher BMI $(\mathrm{M}=21.28$, S.D = 2.28) compared to young female adults BMI $(\mathrm{M}=21.13$, S.D $=2.78)$. In this age group, 5 participants were in the higher BMI range (between 25 to $29.9 \mathrm{~kg} / \mathrm{m}^{2}$ ) and 25 were within the normal BMI values (between 18.5 to $24.9 \mathrm{~kg} / \mathrm{m}^{2}$ ). The values of the present study correlate with [20] findings, wherein the subdivisions of the lung volume were found to differ with age and BMI most markedly so for measures of vital capacity. This is similar to the study by [21] that reported for the same level of adiposity, systemic differences in BMI was found in different gender and age group where, younger males have a significantly higher level of BMI compared to females of the same age group.

On further analysis, Karl Pearson's coefficient correlation analysis was carried out to determine the correlation of Group I (18 to 24 years) with respect to BMI in young males and females. 


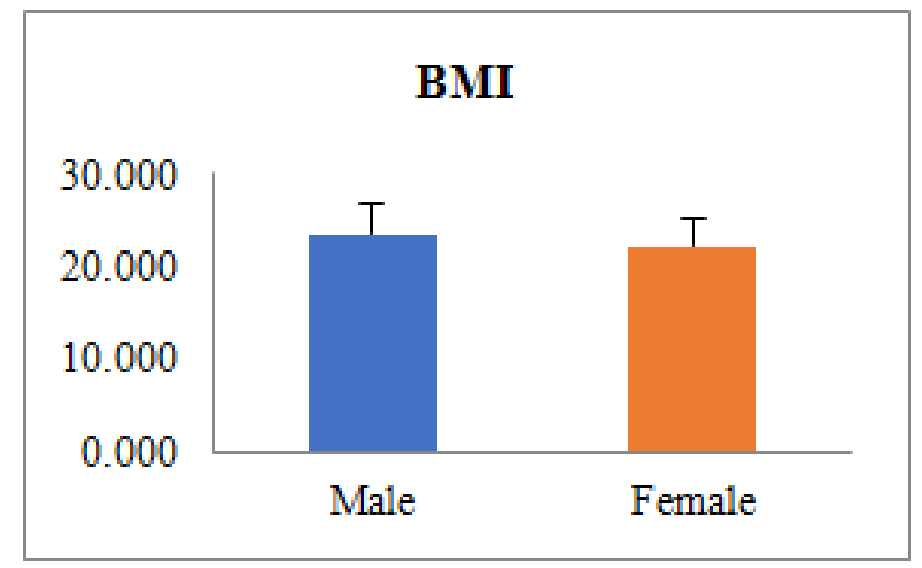

Fig 5:- Shows the effect of age Group (18-24 years) with Body Mass Index

\begin{tabular}{|c|c|c|c|c|c|}
\hline \multirow{3}{*}{$\begin{array}{l}\text { Parameters of } \\
\text { pulmonary } \\
\text { function }\end{array}$} & \multirow{3}{*}{$\begin{array}{l}\mathrm{N}(\text { Mean }=21.21 \\
\quad \mathrm{SD}=2.59)\end{array}$} & \multicolumn{4}{|c|}{ BMI } \\
\hline & & \multicolumn{2}{|c|}{$\begin{array}{c}\text { Male } \\
\text { BMI; Mean= 21.28 SD } 2.36\end{array}$} & \multicolumn{2}{|c|}{$\begin{array}{c}\text { Female } \\
\text { BMI; Mean=21.13 SD } 2.88\end{array}$} \\
\hline & & r-value & p-value & r-value & p-value \\
\hline \multirow{5}{*}{$\begin{array}{l}\text { ERV } \\
\text { TV } \\
\text { IC } \\
\text { FVC } \\
\text { SVC }\end{array}$} & $\begin{array}{l}30 \\
30\end{array}$ & -0.22 & 0.42 & -0.10 & 0.70 \\
\hline & $\begin{array}{l}30 \\
30\end{array}$ & -0.15 & 0.57 & 0.20 & 0.47 \\
\hline & 30 & 0.22 & 0.42 & 0.62 & $0.01^{*}$ \\
\hline & & -0.21 & 0.43 & 0.01 & 0.97 \\
\hline & & 0.16 & 0.54 & 0.35 & 0.19 \\
\hline
\end{tabular}

Table 4:- Correlation for Age Group 18-24 with respect to Body Mass Index

NOTE: ERV- expiratory reserve volume, TV- tidal volume, IC-inspiratory capacity, FVC-forced vital capacity, SVC-slow vital capacity, N- number of participants, BMIbody mass index, S.D- standard deviation, r-correlation coefficient, p- significant value. ${ }^{*}$ Indicates significant at $p<$ $0.05 * *$ Indicates significant at $p<0.01$

Table 4 depicts the Karl Person correlation of age and the parameters of pulmonary functions with Body Mass Index (BMI) with respect to youngest age group I (1824years) with 15 males and 15 females. It could be seen that Expiratory Reserve Volume, Tidal Volume and Forced Vital Capacity were negatively correlated, and Inspiratory Capacity and Slow Vital Capacity were positively correlated for males in this age group with respect to Body Mass Index, with no significance seen among the pulmonary parameters. That is with an increase in age and BMI the ERV, TV and FVC decreases and inspiratory capacity and slow vital capacity increases with age and BMI. Whereas ERV was negatively correlated with BMI, and all the other variables were positively correlated with BMI for females. That is with an increase in age and BMI there was a decrease in ERV and an increase in TV, FVC, SVC and IC. Interestingly, the correlation is significant with $(p<0.01)$ for Inspiratory Capacity for females in the age group of 18 to 24 years.

The inspiratory capacity was significant which could be because 9 females in this age group either had normal weight (18 to $24.9 \mathrm{~kg} / \mathrm{m}^{2}$ ), 3 underweight (below $18 \mathrm{~kg} / \mathrm{m}^{2}$ ) and 2 overweight (between 25 to $29.9 \mathrm{~kg} / \mathrm{m}^{2}$ ) and the younger females generated a higher value for IC which was the second highest pulmonary function. It could also be due to the underlying factor that females have a smaller thorax than men and are therefore able to generate low pressures, despite weaker muscles compared to males. This is supported by the literature finding by [22] where women have ribcage that is angled differently than men and a shorter diaphragm length, that shows women have a greater capacity to expand their lungs and has shown to lend an increase advantage in inspiratory capacity. The following Table 5 describes the effect of age (the next higher age group of 25 to 30 years) in males and females. 
ISSN No:-2456-2165

\begin{tabular}{|c|c|c|c|c|c|}
\hline $\begin{array}{c}\text { Parameters of } \\
\text { pulmonary function }\end{array}$ & $(\mathbf{N}=\mathbf{3 0})$ & Mean & SD & t (28) & p-value \\
\hline \multirow[t]{2}{*}{ ERV } & Male & 1.15 & 0.64 & \multirow[t]{2}{*}{0.71} & \multirow[t]{2}{*}{0.93} \\
\hline & Female & 0.99 & 0.56 & & \\
\hline \multirow[t]{2}{*}{ TV } & Male & 1.58 & 0.73 & \multirow[t]{2}{*}{3.07} & \multirow[t]{2}{*}{$\mathbf{0 . 0 0}^{\text {*** }}$} \\
\hline & Female & 0.93 & 0.33 & & \\
\hline \multirow[t]{2}{*}{ IC } & Male & 2.84 & 0.79 & \multirow[t]{2}{*}{4.64} & \multirow[t]{2}{*}{ 0.01* } \\
\hline & Female & 1.77 & 0.39 & & \\
\hline \multirow[t]{2}{*}{ FVC } & Male & 3.28 & 0.78 & \multirow[t]{2}{*}{4.06} & \multirow[t]{2}{*}{0.59} \\
\hline & Female & 2.24 & 0.61 & & \\
\hline \multirow[t]{2}{*}{ SVC } & Male & 3.99 & 1.20 & \multirow[t]{2}{*}{3.75} & \multirow[t]{2}{*}{0.09} \\
\hline & Female & 2.62 & 0.74 & & \\
\hline
\end{tabular}

Table 5:- Descriptive statistics and t-values for the pulmonary functions of FVC and SVC in the age Group II (25 -30 years) for males and females

NOTE: ERV- expiratory reserve volume, TV- tidal volume, IC-inspiratory capacity, FVC-forced vital capacity, SVC-slow vital capacity, N- number of participants, S.Dstandard deviation, $t$ - two-sample t-test, $\mathrm{p}$ - significant value. ${ }^{*}$ Indicates significant at $p<0.05 * *$ Indicates significant at $p<0.01$

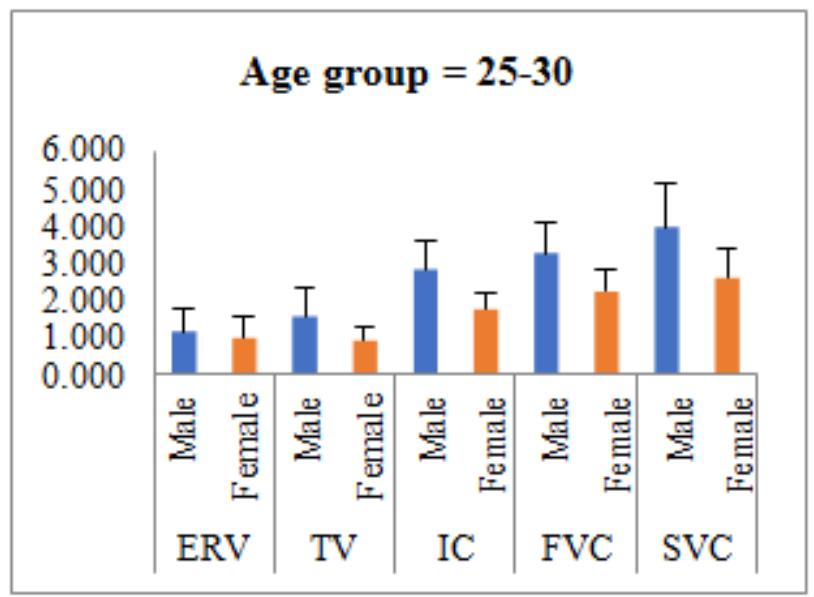

Fig 6:- Represents pulmonary functions for group II (25-30 years)

Table 5 and Fig. 6. shows the descriptive statistics of Mean, Standard Deviation, and t-values obtained from Independent t-test for the age group of 25 to 30 years for 15 males and 15 females for the parameters of pulmonary function. For the next higher age group of 25 to 30 years as shown in figure 7 , the male participants had the highest value for $\mathrm{SVC}$ (Mean= 3.99, $\mathrm{SD}=1.20)$ followed by $\mathrm{FVC}$, $\mathrm{IC}$, TV and lowest for $\operatorname{ERV}($ Mean $=1.15, \mathrm{SD}=$ 0.64).Similarly, the function of SVC (Mean=2.69 SD 1.20) was also highest for the female group, this finding is in accordance with a study by [19] who reported that with aging, larger and more central airways increases in diameter with an increase in anatomic and physiologic dead space. The high value of SVC was followed by FVC, IC, ERV and the lowest for TV (Mean=0.93, $\mathrm{SD}=0.33$ ).
Higher SVC values in males and females could be due to the pulmonary structure and morphological differences with an increase in age. However, it was noticed that there was a subsequent decline in forced expiratory volume and Forced Vital Capacity in the age group of 25 to 30 years as compared to the younger age group of 18 to 24 years, and this could be due to the decline in function that rapidly accelerates with age, as documented by [23] which is due to a relatively larger lung, that takes longer time to empty, also there was a decline in pulmonary recoil with advancing years. The findings established age plays an important role in determining the significance of pulmonary function which are related to the physiological changes that take place across one's span of life [24]

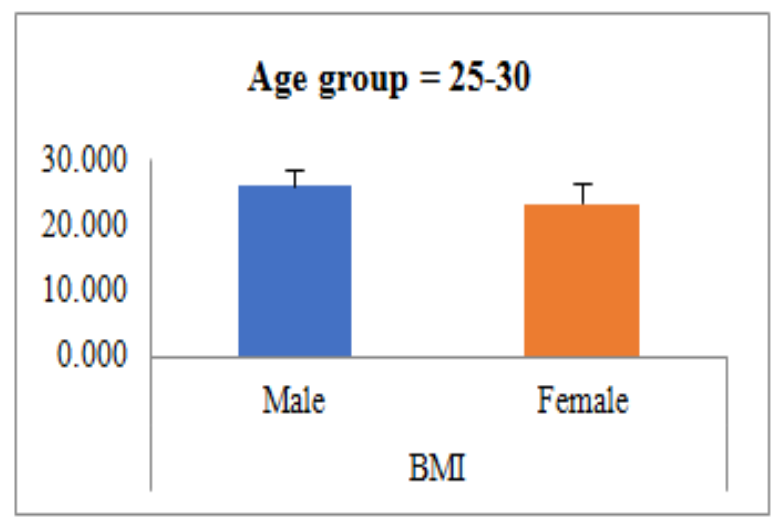

Fig 7:- Shows the effect of age Group II (25-30 years) with respect to Body Mass Index

Fig. 7. shows within the age group of 25 to 30 years, the effect of age on pulmonary functions with respect to BMI in males and females. Males had a higher BMI with an increase in age. In the current study 11 males and 2 females participants were overweight(between 25 to $29.9 \mathrm{~kg} / \mathrm{m}^{2}$ ) in the age group of 25 to 30 years .The findings of the present study are in consonance with the finding of [25] that body composition and spirometry parameters in the male group were significantly greater than in the female group. 
ISSN No:-2456-2165

\begin{tabular}{|c|c|c|c|c|c|}
\hline \multirow{3}{*}{$\begin{array}{l}\text { Parameters of } \\
\text { pulmonary } \\
\text { function }\end{array}$} & \multirow{3}{*}{$\begin{array}{c}\mathrm{N}(\text { Mean }=24.50 \\
\mathrm{SD}=2.94)\end{array}$} & \multicolumn{4}{|c|}{ BMI } \\
\hline & & \multicolumn{2}{|c|}{$\begin{array}{c}\text { Male } \\
\text { BMI; Mean 2.65 SD } 0.62\end{array}$} & \multicolumn{2}{|c|}{$\begin{array}{c}\text { Female } \\
\text { BMI; Mean 1.71, SD } 0.25\end{array}$} \\
\hline & & r-value & p-value & r-value & p-value \\
\hline \multirow{5}{*}{$\begin{array}{l}\text { ERV } \\
\text { TV } \\
\text { IC } \\
\text { FVC } \\
\text { SVC }\end{array}$} & 30 & -0.14 & 0.60 & 0.18 & 0.50 \\
\hline & 30 & -0.38 & 0.15 & 0.40 & 0.13 \\
\hline & 30 & -0.29 & 0.28 & 0.25 & 0.36 \\
\hline & 30 & -0.13 & 0.63 & 0.31 & 0.25 \\
\hline & 30 & -0.26 & 0.33 & 0.20 & 0.46 \\
\hline
\end{tabular}

Table 6:- Correlation of age (25-30 years) with respect to Body Mass Index

NOTE: ERV- expiratory reserve volume, TV- tidal volume, IC-inspiratory capacity, FVC-forced vital capacity, SVC-slow vital capacity, N- number of participants, BMIbody mass index, S.D- standard deviation, r-correlation coefficient, $\mathrm{p}$ - significant value.* Indicates significant at $p<$ $0.05 * *$ Indicates significant at $p<0.00$

Table 6 depicts the Karl Pearson correlation of age and the parameters of pulmonary function with Body Mass Index with respect to age group II (25- 30years) with 15 males and 15 females. It could be seen that Expiratory Reserve Volume, Tidal Volume, Inspiratory Capacity, Forced Vital Capacity and Slow Vital Capacity were negatively correlated for males in this age group with respect to Body Mass Index, with no significance seen among the pulmonary parameters. That is with an increase in age and BMI, the ERV, TV, IC, FVC and SVC decreases it could be because only four males were within the normal BMI values and rest eleven of them were overweight. Whereas all parameters were positively correlated for females and did not show any statistical significance. That is ERV, TV, IC, FVC and SVC increases with an increase in age and with respect to BMI.

The results from the present study show there was no significance in the respiratory parameters, and they are nonlinear with age. The observed differences in lung function may be reflected due to the differences in BMI.
The relationship between FVC, FEV1, and BMI was curvilinear. Lung function appears to increase with BMI at least through the first 60 percentiles of the population [26].

The findings of the present study are also in accordance with [27] findings which is attributable to, the pressing of the diaphragm upwards due to the expanded abdominal volume of overweight individuals. The present study has 13 participants who are overweight (between 25 and $29.9 \mathrm{~kg} / \mathrm{m}^{2}$ ). This also is supported by the findings by [28] were most important changes in pulmonary functions in overweight individuals are due to a decrease in lung compliance which is due to the increased weight of chest wall and the higher position of diaphragm in the thoracic cavity resulting in a decreased lung function which subsequently leads to an increase in the effort of breathing. In addition, the deposition of fat on the chest wall may impede the expansion and excursion of the rib cage, through a direct loading effect or by altering the inter-costal muscle function.

The following Table 7 describes the comparison of both the age groups, the younger adults in the age range of 18 to 24 years and the older group of adults of 25 to 30 years. Both the age groups consisted of 30 participants in each age group, with 15 males and 15 females.

\begin{tabular}{|c|c|c|c|}
\hline $\begin{array}{c}\text { Parameters of pulmonary } \\
\text { function }\end{array}$ & Age group N=60 & Mean & SD \\
\hline \multirow{2}{*}{ ERV } & & & $\mathbf{0 . 0 8}$ \\
\hline \multirow{2}{*}{ TV } & $18-24$ & 1.57 & $\mathbf{0 . 6 0}$ \\
\hline & $25-30$ & 1.38 & $\mathbf{0 . 5 0}$ \\
\hline \multirow{2}{*}{ IC } & $18-24$ & 1.25 & $\mathbf{0 . 6 5}$ \\
\hline \multirow{2}{*}{ FVC } & $25-30$ & 2.29 & $\mathbf{0 . 5 9}$ \\
\hline \multirow{2}{*}{ SVC } & $18-24$ & 2.31 & $\mathbf{0 . 8 2}$ \\
\hline & $25-30$ & 3.17 & $\mathbf{0 . 6 1}$ \\
\hline
\end{tabular}

Table 7:- Descriptive statistics with respect to the age group I and group II

NOTE: ERV- expiratory reserve volume, TV- tidal volume, IC-inspiratory capacity, FVC-forced vital capacity, SVC-slow vital capacity, $\mathrm{N}$ - number of participants, S.D- standard deviation. 


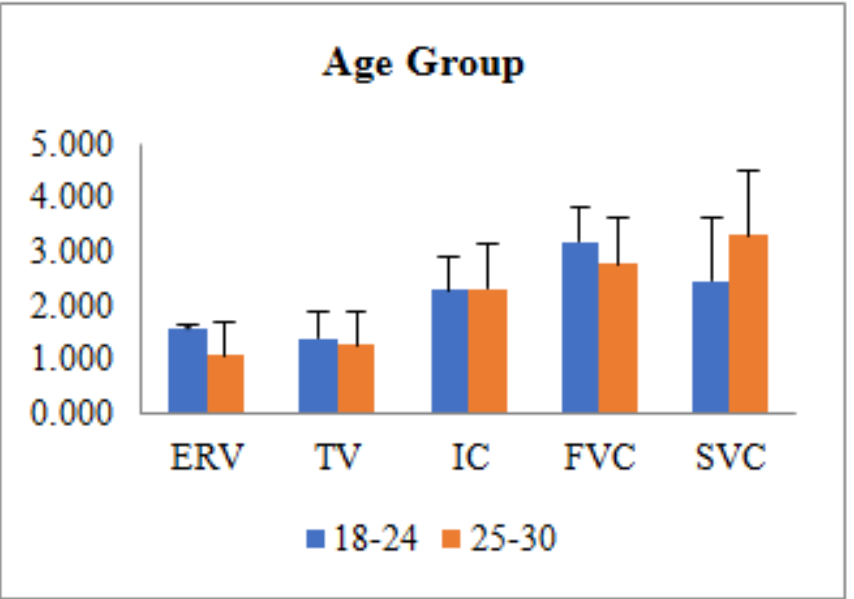

Fig 8:- Represents the pulmonary functions for the age Groups I (18-24 years) and Group II (25-30 years)

Table 7 and Fig. 8. shows the descriptive statistics of Mean, Standard Deviation for the two age groups with 30 participants in each group on the parameters of the pulmonary function of ERV, TV, IC, FVC and SCV. On comparison of the effect of age on the pulmonary functions, it can be seen in Fig.10, that parameters ERV,TV and FVC show higher values in the younger age group of 18 to 24 years compared to the higher age group of 25 to 30 years that showed a slight increase only in the value of IC and a much greater value for SVC.

The findings of the current study are in support with the reports of [29] that with an increase in age there was a significant improvement in Inspiratory Capacity on the contrary expiratory reserve volume decreased linearly. The results of the present study also indicate the linearity in relation with age. As age increases the pulmonary function and BMI increase up to around 30 years and then start declining after the age of 35 which is due to relatively larger lungs, that takes longer time to empty, also there was a decline in pulmonary recoil with advancing years. Which is due to the loss of elasticity of the lung tissues [30].

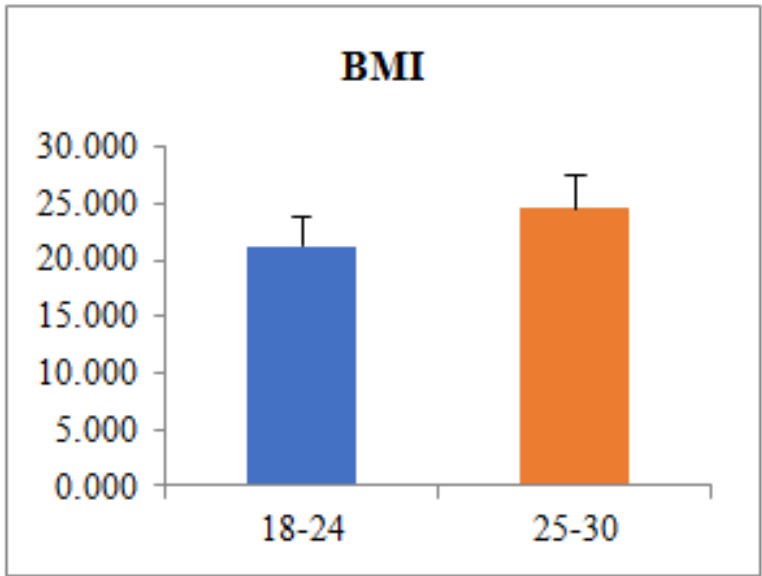

Fig 9:- Represents the pulmonary functions for group I and group II with respect to Body Mass Index

Fig. 9. represents the age groups, I and II, with respect to BMI. Group II (25 to 30 years) depicts an increase in the values of pulmonary functions compared to the younger age group I (18-24 years). In a study done by [23] pointed out the period from late childhood through adolescence, maturation significantly increases pulmonary function with height and age, which are independent of growth and reaches its maximum pulmonary function, later subsequent age-related decline happens in the early or mid-30's. This can be supported by the findings of [31] which indicates that as age increases the pulmonary functions increases with respect to Body Mass Index in young adults. The extend of aging process in the lungs shows a great inter-individual variation [9]. Even in individuals who enjoy good health, there are measurable decrements in the function of the respiratory system with age [32].

Also, when there is related increase in muscle strength with aging, pulmonary function initially increases in parallel with weight gain. Due to this muscle effect higher BMI in healthy adults is accompanied by an increase in pulmonary function. Similar study done by [33] reported increased BMI did not impair pulmonary function in the higher age group.

\begin{tabular}{|c|c|c|c|c|c|}
\hline \multirow{3}{*}{$\begin{array}{l}\text { Parameters of } \\
\text { pulmonary function }\end{array}$} & \multirow{3}{*}{$\begin{array}{c}\mathrm{N} \\
(\text { Mean }=\mathbf{2 2 . 8 5 . 5 0} \\
\mathrm{SD}=\mathbf{3 . 2 1})\end{array}$} & \multicolumn{4}{|c|}{ BMI } \\
\hline & & \multicolumn{2}{|c|}{$\begin{array}{c}\text { Male } \\
\text { BMI; Mean 2.17 SD } 0.58\end{array}$} & \multicolumn{2}{|c|}{$\begin{array}{c}\text { Female } \\
\text { BMI; Mean 2.13, SD 0.67 }\end{array}$} \\
\hline & & r-value & p-value & r-value & p-value \\
\hline \multirow{5}{*}{$\begin{array}{l}\text { ERV } \\
\text { TV } \\
\text { IC } \\
\text { FVC } \\
\text { SVC }\end{array}$} & 60 & -0.14 & 0.60 & 0.18 & 0.50 \\
\hline & 60 & -0.38 & 0.15 & 0.40 & 0.13 \\
\hline & 60 & -0.29 & 0.28 & 0.25 & 0.36 \\
\hline & 60 & -0.13 & 0.63 & 0.31 & 0.25 \\
\hline & 60 & -0.26 & 0.33 & 0.20 & 0.46 \\
\hline
\end{tabular}

Table 8:- Correlation for Age group I (18-24years) and group II (25-30 years) with respect to BMI

NOTE: ERV- expiratory reserve volume, TV- tidal volume, IC-inspiratory capacity, FVC-forced vital capacity, SVC-slow vital capacity, N- number of participants, BMIbody mass index, S.D- standard deviation, r-correlation coefficient, p- significant value.
In Table 8 depicts the Karl Pearson correlation of age and the parameters of pulmonary function with Body Mass Index by comparing group I (18-24 years) and group II (25-30 years) with 30 males and 30 females, respectively. In group I Expiratory Reserve Volume, Tidal Volume and Forced Vital Capacity are negatively correlated and 
Inspiratory Capacity and Slow Vital Capacity are positively correlated. That is with increase in age and BMI there was a decrease in ERV, TV, FVC and an increase in IC and SVC. In group I, 21 individuals were within normal BMI (18 to $24.9 \mathrm{~kg} / \mathrm{m}^{2}$ ), 4 were underweight (below $18.5 \mathrm{~kg} / \mathrm{m}^{2}$ ) and 5 were overweight (between 25 to $29.9 \mathrm{~kg} / \mathrm{m}^{2}$ ). In the 25 to 30 years, all the parameters are positively correlated. That is with an increase in age and BMI there was an increase ERV, TV, FVC, IC and SVC. Here 15 participants were within the normal $\mathrm{BMI}$ (between 18 to $24.9 \mathrm{~kg} / \mathrm{m}^{2}$ ), 12 individuals were under weight ( below $18.5 \mathrm{~kg} / \mathrm{m}^{2}$ ) 2 were overweight(between 25 and $29.9 \mathrm{~kg} / \mathrm{m}^{2}$ ) and 1 individual was obese(above 30), however none of these parameters are statistically significant in both the age groups.
These changes seen in the pulmonary function between age groups is supported by findings of [34], where differences seen between the age groups are probably a consequence of the physiological effect of aging and also is related to the smaller airways in younger age group. Elderly subjects generating less positive intrapleural pressures on expiration, thereby failing to compress the small airways in the forced maneuver to the same extent as younger subjects.

C. To determine the effect of Gender and its correlation on pulmonary functions of Forced Vital Capacity and Slow Vital Capacity with respect to Body Mass Index.

Table 9 shows the effect of gender (males) on the pulmonary functions of FVC and SVC in Group I (18 to 24 years) and group II (25 to 30 years).

\begin{tabular}{|c|c|c|c|c|c|}
\hline $\begin{array}{l}\text { Parameter of } \\
\text { pulmonary function }\end{array}$ & $\begin{array}{c}\text { Age group }(\mathrm{N}=30 \\
\text { males })\end{array}$ & Mean & SD & T (28) & p-value \\
\hline \multirow[t]{2}{*}{ ERV } & $18-24$ & 1.62 & 0.04 & \multirow[t]{2}{*}{2.81} & \multirow[t]{2}{*}{$0.00^{* *}$} \\
\hline & $25-30$ & 1.15 & 0.64 & & \\
\hline \multirow[t]{2}{*}{ TV } & $18-24$ & 1.57 & 0.61 & \multirow[t]{2}{*}{-0.02} & \multirow[t]{2}{*}{0.12} \\
\hline & $25-30$ & 1.58 & 0.73 & & \\
\hline \multirow[t]{2}{*}{ IC } & $18-24$ & 2.68 & 0.48 & \multirow[t]{2}{*}{-0.66} & \multirow[t]{2}{*}{$0.04^{*}$} \\
\hline & $25-30$ & 2.84 & 0.79 & & \\
\hline \multirow{2}{*}{ FVC } & $18-24$ & 3.74 & 0.22 & \multirow[t]{2}{*}{2.17} & \multirow[t]{2}{*}{$\mathbf{0 . 0 0}^{* *}$} \\
\hline & $25-30$ & 3.28 & 0.78 & & \\
\hline \multirow[t]{2}{*}{ SVC } & $18-24$ & 3.55 & 0.50 & \multirow[t]{2}{*}{-1.30} & \multirow[t]{2}{*}{$0.01^{*}$} \\
\hline & $25-30$ & 3.99 & 1.20 & & \\
\hline
\end{tabular}

Table 9:- Descriptive statistics and t-values for the pulmonary functions for males across the age Group I (18-24 years) and Group II (25-30 years)

NOTE: ERV- expiratory reserve volume, TV- tidal volume, IC-inspiratory capacity, FVC-forced vital capacity, SVC-slow vital capacity, N- number of male participants, S.D- standard deviation, t- two-sample t-test, $\mathrm{p}$ - significant value.* Indicates significant at $p<0.05 * *$ Indicates significant at $p<0.01$

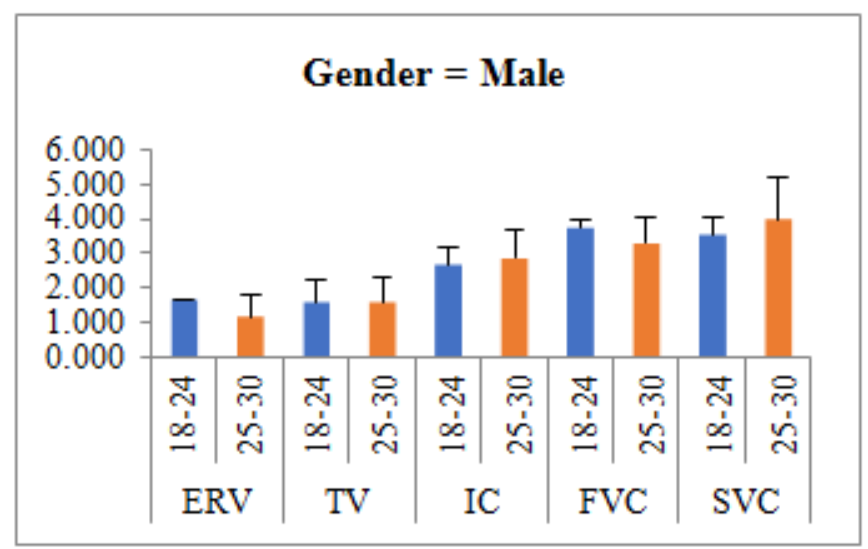

Fig 10:- represents pulmonary function for males across group I (18-24 years) and group II (25-30 years)
Table 9 and Fig. 10. shows the descriptive statistical analysis of Mean, Standard Deviation, and t- values obtained for the pulmonary functions for males across age group I and group II. Th8re were 15 males in each group. As seen in Table 9 and Fig. 12 Mean values for males were higher for slow vital capacity $(\mathrm{M}=3.99, \mathrm{SD}=1.20)$ in group II, followed by forced vital capacity $(\mathrm{M}=3.74, \mathrm{SD}=0.22)$ in group $\mathrm{I}$, inspiratory capacity $(\mathrm{M}=2.84, \mathrm{SD}=0.79)$ in group II, expiratory reserve volume $(\mathrm{M}=1.62, \mathrm{SD}=0.04)$ in group I and tidal volume $(\mathrm{M}=1.58, \mathrm{SD}=0.73)$ in group II. From our study it is evident expiratory reserve volume $(p<0.00)$, inspiratory capacity $(p<0.04)$, forced vital capacity $(p<0.00)$ and slow vital capacity $(p<0.01)$ were statistically significant. This might be due to the level of physical activity in males, which can also be related to the height among the male participants.

The current study is in line with the study by [35] which reported an increase in physical activity can improve the fitness of the cardiorespiratory and in turn can be attributed to an increase in the strength of respiratory muscles. The predominant diaphragmatic breathing in men has been linked to the male thoracic morphology (wider at the caudal part) to the greater medio lateral expansion of the lower lungs and to their more pyramidal shape [36]. 


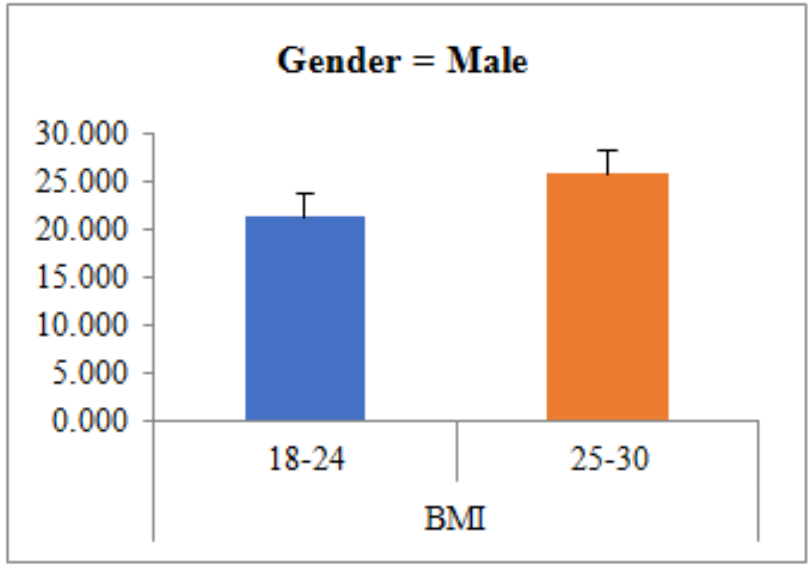

Fig 11:- Represents the effect of males across age Group I (18-24years) and Group II (25-30 years) with respect to Body Mass Index
Current study is supported by [37] that noticed Fig. 11. shows the effect of males across age Group I (18 to 24 years) and group II (25-30 years) with respect to BMI. It could be seen that males of group II (25- 30 years) had higher BMI $(\mathrm{M}=21.28, \mathrm{~S} . \mathrm{D}=2.28)$ compared to males in group I (18- 24 years). 11 participants were in the higher BMI range (between 25 and $29.9 \mathrm{~kg} / \mathrm{m}^{2}$ ) due to overweight in group II, whereas in group I majority of the males $(n=12)$ where above the normal BMI range (between 18.5 to $24.9 \mathrm{~kg} / \mathrm{m}^{2}$ ). adult males at constant height, VC increased with weight through certain level of average weight and decreased slightly with further increases in weight. The magnitude of muscularity obesity effect varies with both height and age. We believe that the increase of lung function with weight may reflect increasing muscle force, while the decrease with further weight increase probably reflects "the mere circumstance of fat preventing the mobility of the thoracic boundaries.

\begin{tabular}{|c|c|c|c|c|c|}
\hline $\begin{array}{l}\text { Parameters of } \\
\text { pulmonary } \\
\text { function }\end{array}$ & $\begin{array}{c}\text { Age group ( } N=30 \\
\text { females) }\end{array}$ & Mean & SD & $\mathbf{t}(\mathbf{2 8})$ & p-value \\
\hline \multirow[t]{2}{*}{ ERV } & $18-24$ & 1.51 & 0.06 & \multirow[t]{2}{*}{3.51} & \multirow{2}{*}{$0.00^{* * *}$} \\
\hline & $25-30$ & 0.99 & 0.56 & & \\
\hline \multirow[t]{2}{*}{ TV } & $18-24$ & 1.20 & 0.28 & \multirow[t]{2}{*}{2.34} & \multirow[t]{2}{*}{0.63} \\
\hline & $25-30$ & 0.93 & 0.33 & & \\
\hline \multirow[t]{2}{*}{ IC } & $18-24$ & 1.89 & 0.40 & \multirow[t]{2}{*}{0.82} & \multirow[t]{2}{*}{0.82} \\
\hline & $25-30$ & 1.77 & 0.39 & & \\
\hline \multirow[t]{2}{*}{$\overline{F V C}$} & $18-24$ & 2.61 & 0.23 & \multirow[t]{2}{*}{2.16} & \multirow{2}{*}{$0.00^{* *}$} \\
\hline & $25-30$ & 2.24 & 0.61 & & \\
\hline \multirow[t]{2}{*}{ SVC } & $18-24$ & 1.36 & 0.02 & \multirow[t]{2}{*}{-6.50} & \multirow[t]{2}{*}{$0.00^{* * *}$} \\
\hline & $25-30$ & 2.62 & 0.74 & & \\
\hline
\end{tabular}

Table 10:- Descriptive statistics and t-values for the pulmonary functions for females across the age Group I (18-24 years) and Group II (25-30 years)

NOTE: ERV- expiratory reserve volume, TV- tidal volume, IC-inspiratory capacity, FVC-forced vital capacity, SVC-slow vital capacity, N- number of female participants, S.D- standard deviation, t- two-sample t-test, $\mathrm{p}$ - significant value.* Indicates significant at $p<0.05 * *$ Indicates significant at $p<0.01$

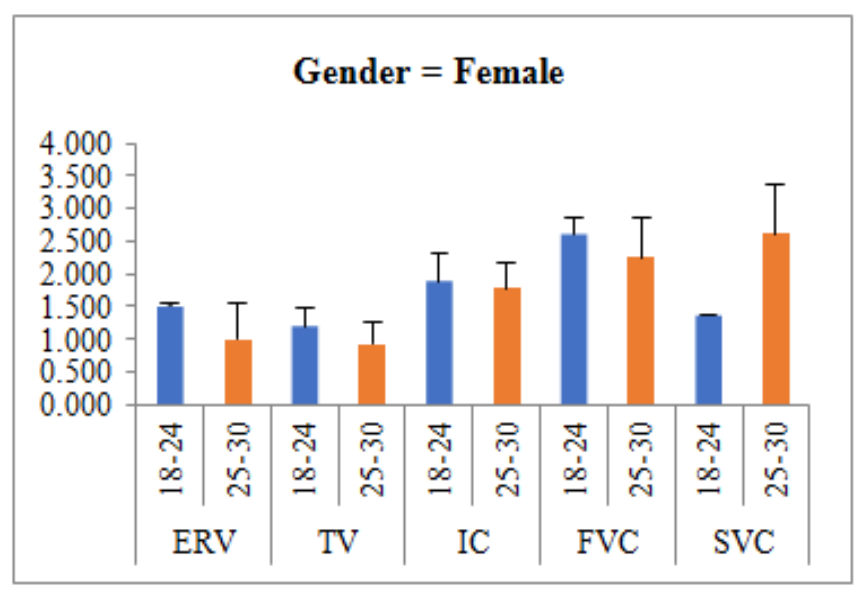

Fig 12:- Represents pulmonary function for females across group I (18-24 years) and group II (25-30 years)
Table 10 and Fig. 12. shows the descriptive statistical analysis of Mean, Standard Deviation, and t- values obtained for the pulmonary functions for females across age group I and group II. There were 15 females in each group. As seen in Table 10 and Fig.14 Mean values for females were higher for slow vital capacity $(\mathrm{M}=2.62, \mathrm{SD}=0.74)$ in group II, followed by forced vital capacity $(\mathrm{M}=2.61, \mathrm{SD}=$ $0.23)$ in group $\mathrm{I}$, inspiratory capacity $(\mathrm{M}=1.89, \mathrm{SD}=0.40)$ in group I, expiratory reserve volume $(\mathrm{M}=1.51, \mathrm{SD}=0.06)$ in group I and tidal volume $(\mathrm{M}=1.20, \mathrm{SD}=0.28)$ in group $\mathrm{I}$. From our study it is evident expiratory reserve volume $(p<0.00)$, forced vital capacity $(p<0.00)$ and slow vital capacity $(p<0.00)$ were statistically significant. This might be due to the size of the lung and ribcage in females, which can also be related to the lower height among the female participants.

The present findings are supported by [38] findings that showed there was an increased action of the inspiratory ribcage muscles in women. It is also in accordance with the findings by [39] which stated a greater inclination of the ribs in females may put the inspiratory rib cage muscles at a better mechanical advantage. The more declined ribs of women make the intercostal muscles raise the ribs more 
efficiently and produce more pronounced thoracic breathing.

Other literature also supports this finding with [40] that showed female subjects can exhale a higher proportion of FVC during the first second in comparison with their male counterparts, which can be explained as a result due to the presence of a relatively shorter length of tracheobronchial tree in females.

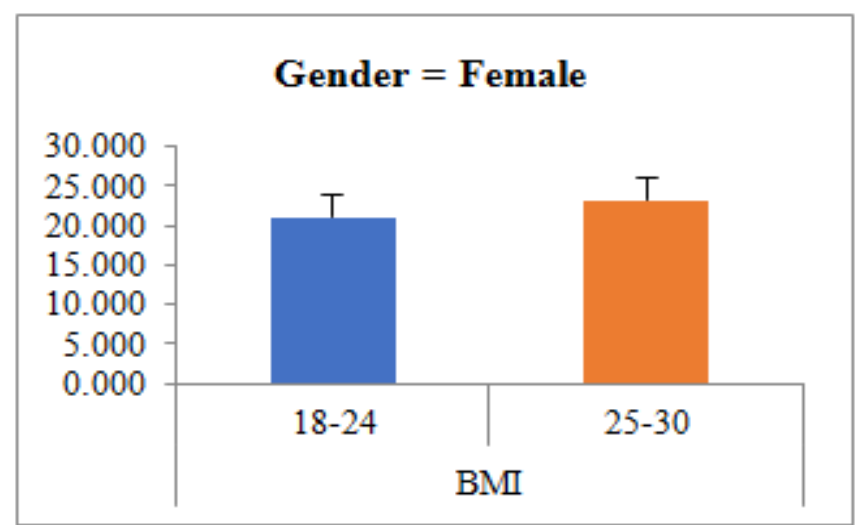

Fig 13:- Represents the effect of females across age groups I (18-24 years) and group II(25-30 years) with respect to Body Mass Index
Fig. 13. shows the effect of females across age Group I (18 to 24 years) and group II (25-30 years) with respect to Body Mass Index. It could be seen that females of group II (25- 30 years) had higher BMI $(\mathrm{M}=23.20$, S.D $=2.96)$ compared to females in group I (18- 24 years). 11 participants were within the normal BMI range(between 18.5 to $24.9 \mathrm{~kg} / \mathrm{m}^{2}$ ), 2 were overweight(between 25 to $29.9 \mathrm{~kg} / \mathrm{m}^{2}$ ) and 1 obese (above $\left.30 \mathrm{~kg} / \mathrm{m}^{2}\right)$ in group II $(25-30$ years) whereas in group I only 9 participants were within normal range(between 18.5 to $24.9 \mathrm{~kg} / \mathrm{m}^{2}$ )and 5 were under weight(below $18 \mathrm{~kg} / \mathrm{m}^{2}$ ) and 1 obese(above $\left.30 \mathrm{~kg} / \mathrm{m}^{2}\right)$.

Even with an increase in BMI for females, the pulmonary functions were higher because body fat is more peripherally distributed in women [41].

The finding of the present study is similar with the study by [42] which pointed out, Changes in pulmonary function seen among females can be due to the changes in their inspiratory and expiratory muscle endurance and chest wall compliance with an increase in Body Mass Index.

\begin{tabular}{|c|c|c|c|}
\hline $\begin{array}{c}\text { Parameters of } \\
\text { pulmonary function }\end{array}$ & Gender (N=60) & Mean & SD \\
\hline ERV & Male & 1.39 & 0.51 \\
& Female & 1.25 & 0.47 \\
\cline { 2 - 4 } TV & Male & 1.57 & 0.66 \\
\cline { 2 - 4 } & Female & 2.7 & 0.33 \\
\hline \multirow{2}{*}{ IC } & Male & 1.83 & 0.65 \\
\hline FVC & Female & 3.51 & 0.39 \\
\hline \multirow{2}{*}{ SVC } & Male & 2.42 & 0.61 \\
\cline { 2 - 4 } & Female & 3.77 & 0.49 \\
\cline { 2 - 4 } & Male & 1.99 & 0.93 \\
\hline
\end{tabular}

Table 11:- Descriptive statistics with respect to male and female

NOTE: ERV- expiratory reserve volume, TV- tidal volume, IC-inspiratory capacity, FVC-forced vital capacity, SVC-slow vital capacity, $\mathrm{N}$ - number of participants, S.D- standard deviation

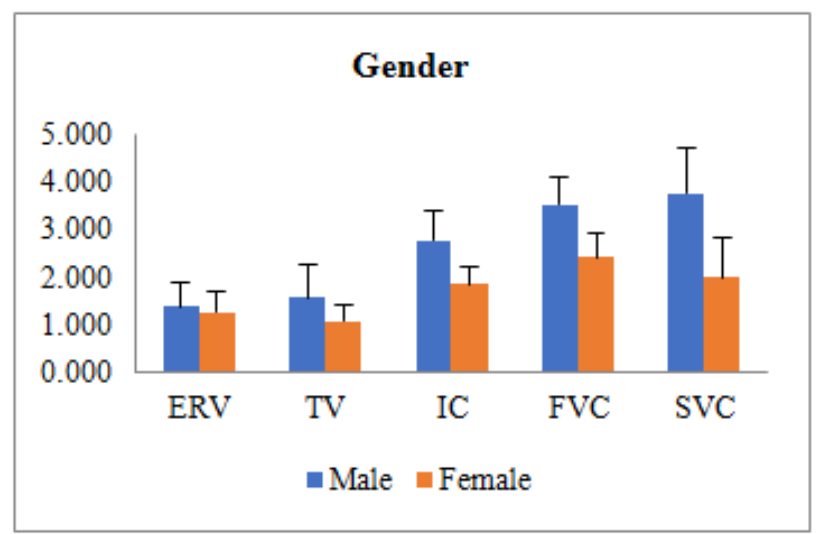

Fig 14:- Represents the pulmonary functions for males and females 
Table 11 and Fig. 14 shows the descriptive statistics of Mean, Standard Deviation for males and females with 30 male and 30 female participants on the parameters of the pulmonary function of ERV, TV, IC, FVC and SCV. On comparison of the effect of gender on the pulmonary functions, it can be seen in Fig.16, that parameters ERV, TV, IC, FVC and SVC show higher values in males compared to females.

The literature finding states that men have a greater number of alveoli per unit and their alveoli are larger and have greater compliance and are expected to have higher values of pulmonary function as compared to females [43]

Also, it can be supported by [44] findings, although the intrinsic elasticity of lung parenchyma is similar between sexes, the recoil pressure differs because of the difference in lung shape and size, which is more pyramidal in males. In addition, [45] reported that Indian men had higher mean values of FVC, FEV 1, and FEV 1/FVC\% than women, as they explain that men have bigger lungs for the same height than women; muscularity in men accounts higher value of lung functions and sex hormones in addition to the anatomical and physiological differences may also be responsible for the gender differences in lung function.

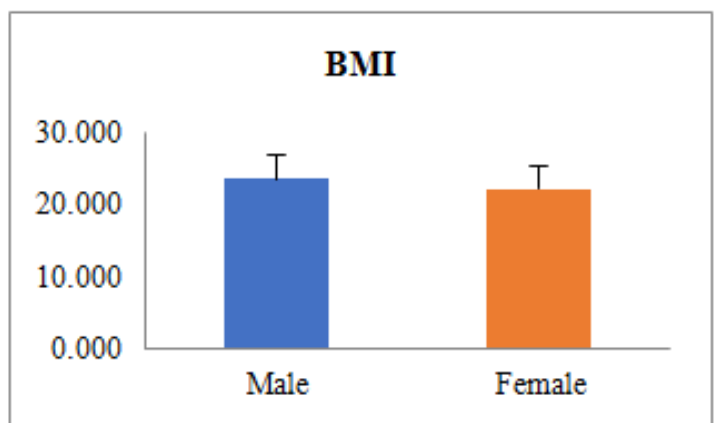

Fig 15:- Represents the pulmonary functions for males and females with respect to Body Mass Index

It can be seen from Fig.17 Males have higher values of pulmonary functions compared to females. This finding is in line with [46] which reported Males between the age 18-30 years did not show any decline in pulmonary function, because even with an increase in Body Mass Index the maximal lung function was maintained.

In our study males have higher values which could be due to their higher level of physical activity which can lead to stronger muscles rather than higher fat deposit even with an increase in BMI. In this study, among males 16 participants were within normal BMI range (between 18 to $24.9 \mathrm{~kg} / \mathrm{m}^{2}$ ), only 1 participant was underweight (below $18 \mathrm{~kg} / \mathrm{m}^{2}$ ) and 13 participants were overweight (between 25 to $29.9 \mathrm{~kg} / \mathrm{m}^{2}$ ). This is similar to the findings reported by [47] which reported in males fat free mass contribute to most of the body weight. Fat free mass is mainly composed of muscles and is associated with the level of physical activity and height, it independently effects respiratory muscles. whereas body fat percentage of females was higher than that of males.

\begin{tabular}{|c|c|c|c|c|c|}
\hline \multirow{3}{*}{$\begin{array}{l}\text { Parameters } \\
\text { of pulmonary } \\
\text { function }\end{array}$} & \multirow{3}{*}{$\begin{array}{c}\mathrm{N} \\
(\text { Mean }=\mathbf{2 2 . 8 5 . 5 0} \\
\mathrm{SD}=\mathbf{3 . 2 1})\end{array}$} & \multicolumn{4}{|c|}{ BMI } \\
\hline & & \multicolumn{2}{|c|}{$\begin{array}{c}\text { Male } \\
\text { BMI; Mean 2.17 SD } 0.58\end{array}$} & \multicolumn{2}{|c|}{$\begin{array}{c}\text { Female } \\
\text { BMI; Mean 2.13, SD 0.67 }\end{array}$} \\
\hline & & r-value & p-value & r-value & p-value \\
\hline \multirow{2}{*}{$\begin{array}{l}\text { ERV } \\
\text { TV }\end{array}$} & 60 & -0.40 & 0.02 & -0.09 & 0.63 \\
\hline & & -0.19 & 0.30 & 0.13 & 0.49 \\
\hline \multirow[t]{2}{*}{ IC } & 60 & & & & \\
\hline & & 0.02 & 0.91 & 0.35 & 0.05 \\
\hline \multirow{4}{*}{$\begin{array}{l}\text { FVC } \\
\text { SVC }\end{array}$} & 60 & & & & \\
\hline & 60 & & & & \\
\hline & & -0.35 & 0.05 & 0.05 & 0.77 \\
\hline & & 0.08 & 0.66 & 0.34 & 0.05 \\
\hline
\end{tabular}

Table 12:- Correlation for males and females with respect to Body Mass Index

NOTE: ERV- expiratory reserve volume, TV- tidal volume, IC-inspiratory capacity, FVC-forced vital capacity, SVC-slow vital capacity, N- number of participants, BMIbody mass index, $r$ - correlation coefficient, $p$ - significant value.* Indicates significant at $p<0.05 * *$ Indicates significant at $p<0.01$

In Table 12 depicts the Karl Pearson correlation of gender on the parameters of pulmonary function with Body
Mass Index across 30 males and 30 females, respectively. Among male's the expiratory reserve volume, tidal volume and forced vital capacity were negatively correlated and inspiratory capacity and slow vital capacity were positively correlated. That is with increase in BMI there was a decrease in ERV, TV, FVC and an increase in IC and SVC. Among males, 16 individuals were within normal BMI, 1 were underweight (below $18.5 \mathrm{~kg} / \mathrm{m}^{2}$ ) and 13 were 
overweight (between 25 to $29.9 \mathrm{~kg} / \mathrm{m}^{2}$ ). In females, expiratory reserve volume was negatively correlated and tidal volume, inspiratory capacity, forced vital capacity and slow vital capacity were positively correlated. Hence with an increase in BMI there was an increase TV, FVC, IC and SVC and decrease in ERV. Here 20 participants were within the normal BMI (between 18.5 to $24.9 \mathrm{~kg} / \mathrm{m}^{2}$ ), 4 individuals were under weight (below $18.5 \mathrm{~kg} / \mathrm{m}^{2}$ ), 5 were overweight (between 25 to $39.9 \mathrm{~kg} / \mathrm{m}^{2}$ ) and 1 individual was obese (above $30 \mathrm{~kg} / \mathrm{m}^{2}$ ), however only forced vital capacity were statistically significant among males, whereas inspiratory capacity and slow vital capacity were statistically significant among females.

These changes seen in the pulmonary function between gender is supported by [6] as airway size and lung dimensions are significantly different between males and females. Women have smaller airways relative to lung size than men, also women are characterized by smaller ratios at a given size than men of comparable age.

This is accordance with the finding by [48] that stated, males have a greater ribcage volume and are horizontally oriented than those of females, therefore the difference in ribcage also affects the chest wall. Interestingly thoracic and abdominal volume are higher in men only as absolute values, whereas they are similar to women when expressed as percentage of total chest wall volume, also in females there is a greater contribution of inspiratory ribcage muscles. Men, in fact, also have significantly larger mean values for all pulmonary variables, both volumes and flows, except resistance which is significantly lower in females.

\section{SUMMARY AND CONCLUSION}

The current study focused on how young healthy adults in the age range of 18 to 30 years alter their pulmonary function with respect to age and gender and Body Mass Index. To the best of our knowledge not many studies have been conducted to gather information regarding pulmonary function test in these age group. Sixty participants between the age range of 18 to 30 years were taken for the study. Participants were subdivided into 2 age groups. group I (18 to 24 years) and group II (25 to 30 years) each group having 15 males and 15 females respectively. participants were select after a brief questionnaire interview A written consent form was obtained from each participant and ethical guideline for bio behavioral research, AIISH (2009) was followed for the study. The main objectives of the study were to find out the effect of age and gender with respect to BMI on forced vital capacity and slow vital capacity. General procedure were explained to the participants. For measuring forced vital capacity, the participants were instructed to blow out as hard and fast as possible and continue blowing until no more air can be exhaled, whereas for slow vital capacity both inhalation and exhalation were performed to the maximum extent but slowly and the best values of the maneuvers were documented.
The parameters of pulmonary function considered for the analysis were expiratory reserve volume, tidal volume, inspiratory capacity, forced vital capacity and slow vital capacity. Statistical analysis was carried out and the results revealed a normal distribution. In two-way MANOVA analysis age, gender, age and gender interaction effect were significant in the study. The analysis focused within and across age group comparison and descriptive statistical analysis of Mean, Standard Deviation, and t-values was obtained for the pulmonary functions. Further, Karl Pearson's coefficient correlation analysis was also done, and our findings revealed that group II (25-30 years) has higher pulmonary function compared to group I (18-24 years) with respect to body mass index. As age increases there was an increase in body mass index and the lung volume also increased. These results of the present study are in consonance with the studies reported [30]. As age increases the pulmonary function and BMI increase up to around 30 years and then start declining after the age of 35 , Which is due to the loss of elasticity of the lung tissues. Age increases the pulmonary functions increases with respect to Body Mass Index in young adults [31]. The extend of aging process in the lungs shows a great interindividual variation [9].

Across gender comparison the findings of the present study revealed males had higher pulmonary function compared to females in both the age group, also males in group I (25-30years) had better pulmonary function compared to males in group II(18-24 years) this is in line with studies by [45] that reported Indian men had higher mean values of FVC, FEV 1, and FEV 1/FVC\% than women, as they explain that men have bigger lungs for the same height than women; muscularity in men accounts higher value of lung functions and sex hormones in addition to the anatomical and physiological differences may also be responsible for the gender differences in lung function. With respect to an increase in body mass index, there was an increase in pulmonary function seen in males compared to females.

It can be concluded from the current study that pulmonary function remains the major biological variable that is significantly affected by age, gender, and body mass index. The lung functions show greater inter- individual variations. It is necessary to have separate reference values from population studies, which can be used as standard clinical references for that age, gender, and BMI. In future Spirometry testing can be used as an injunct to clinical assessment and management of speech and voice disorders based on the lung functions.

The study has its limitations; the number of participants taken for the study was less. Spirometry procedure is effort dependent and requires a motivated participant, and calibration of the equipment must be maintained on a timely basis, otherwise there can be chance of getting false values. Further studies are necessary to use this value in the clinical environment. However, in future one can expect to see a progression in measurement and analysis of respiratory functions. 


\section{ACKNOWLEDGEMENTS}

I would like to thank my guide Dr. Reeny Roy, Associate Professor, Naseema Institute of Speech and Hearing, for her constant guidance and support throughout. I thank my participants for their involvement, time and cooperation in the study.

\section{REFERENCES}

[1]. Kent, R. D., Read, C., \& Kent, R. D. (1992). The acoustic analysis of speech (Vol. 58). San Diego: Singular Publishing Group.

[2]. Hoshiko, M. S. (1965). Lung volume for initiation of phonation. Journal of applied physiology, 20(3), 480482.

[3]. Russell, N. K., \& Stathopoulos, E. (1988). Lung volume changes in children and adults during speech production. Journal of Speech, Language, and Hearing Research, 31(2), 146- 155.

[4]. Incebay, Ö., Köse, A., Aydinli, F. E., \& Özcebe, E. (2018). The effects of age and gender on laryngeal aerodynamics in the children population. Journal of Voice

[5]. Weinrich, B., Salz, B., \& Hughes, M. (2005). Aerodynamic measurements: normative data for children ages 6: 0 to 10: 11 years. Journal of Voice, 19(3), 326-339.

[6]. Mead, J. (1980). Dysanapsis in normal lungs assessed by the relationship between maximal flow, static recoil, and vital capacity. American review of respiratory disease, 121(2), 339-342.

[7]. Zaugg, M. \& Lucchinetti, E. 2000. Respiratory function in the elderly. Anesthesiology Clin. North America, 18: 47-58

[8]. Dempsey, J. A. and Seals, D. R. 1995. Aging, exercise and cardiopulmonary function.InHolloszy,

J. (Ed.) Perspectives in exercise science. New York: Williams \&Wilkins, 4(1): 685-693

[9]. Thurlbeck, W. M. and Wright, J. L. 1999. The Aging Lung. In: Thurlbeck's chronic airflow obstruction.Canada: Hamilton, 2(1): 128-31.

[10]. Woo, J. \& Pang, J. 1988. Spirometry in healthy elderly Chinese. Thorax, 43: 617-20

[11]. Rio, F. G., Pino, J. M., Dorgham, A. and Villamor, A. J. 2004. Spirometric reference equations for European females and males aged 65-85 years. Eur. Respire. J.,24: 397-405.

[12]. Wang, X., Dockery, D. W., Wypij, D., Fay, M. E., \& Ferris Jr, B. G. (1993). Pulmonary function between 6 and 18 years of age. Pediatric pulmonology, 15(2), 75-88.

[13]. Fortis, S., Corazalla, E. O., Wang, Q., \& Kim, H. J. (2015). The difference between slow and forced vital capacity increases with increasing body mass index: a paradoxical difference in low and normal body mass indices. Respiratory care, 60(1), 113-118.
[14]. Culver, B. H. and Butler, J. 1985. Alterations in pulmonary function. In: Principles of Geriatric

[15]. Vijayan, V. K., Sankaran, K., Venkatesan, P., \& Kuppurao, K. V. (1993). Prediction equations for maximal voluntary ventilation in non-smoking normal subjects in Madras. Indian Journal of Physiology and Pharmacology, 37(1), 138-140.

[16]. Chen, H. I., \& Kuo, C. S. (1989). Relationship between respiratory muscle function and age, sex, and other factors. Journal of Applied Physiology, 66(2), 943-948.

[17]. Lutfi, M. F. (2017). The physiological basis and clinical significance of lung volume measurements. Multidisciplinary respiratory medicine, 12(1), 3.

[18]. Fry, D. L., \& Hyatt, R. E. (1960). Pulmonary mechanics: a unified analysis of the relationship between pressure, volume and gasflow in the lungs of normal and diseased human subjects. The American journal of medicine, 29(4), 672-689.

[19]. Wahba, W. M. (1983). Influence of aging on lung function-clinical significance of changes from age twenty. Anesthesia \& Analgesia, 62(8), 764-776.

[20]. Hoit, J. D., \& Hixon, T. J. (1987). Age and speech breathing. Journal of Speech, Language, and Hearing Research, 30(3), 351-366.

[21]. Nevill, A. M., \&Metsios, G. S. (2015). The need to redefine age-and gender-specific overweight and obese body mass index cutoff points. Nutrition \& diabetes, 5(11), e186-e186.

[22]. Hopkins, E., \& Sharma, S. (2019). Physiology, functional residual capacity.

[23]. Burrows, B., Cline, M. G., Knudson, R. J., Taussig, L. M., \&Lehowitz, M. D. (1983). A descriptive analysis of the growth and decline of the FVC and FEV1. Chest, 83(5), 717-724.

[24]. Peralta, G. P., Marcon, A., Carsin, A. E., Abramson, M. J., Accordini, S., Amaral, A. F., ... \&Demoly, P. (2020). Body mass index and weight change are associated with adult lung function trajectories: the prospective ECRHS study. Thorax, 75(4),313-320.

[25]. Shin, Y. S., Kim, J. H., Park, J., \& Kim, J. (2015). Analysis of the respirogram phase of normal volunteers according to gender for healthy science research. Toxicology and Environmental Health Sciences, 7(2), 105-111.

[26]. Gao, C., Zhang, X., Wang, D., Wang, Z., Li, J., \& Li, Z. (2018). Reference values for lung function screening in 10-to 81-year-old, healthy, neversmoking residents of Southeast China. Medicine, 97(34).

[27]. Koenig, S. M. (2001). Pulmonary complications of obesity. The American journal of the medical sciences, 321(4), 249-279.

[28]. Parameswaran, K., Todd, D. C., \&Soth, M. (2006). Altered respiratory physiology in obesity. Canadian respiratory journal, 13(4), 203-210. 
[29]. Deesomchok, A., Ora, J., Webb, K. A., Froese, S., Moran-Mendoza, O., Forkert, L., \& O'Donnell, D. E. (2009). The Impact of Obesity on Pulmonary Function Measurements in Patients with COPD across GOLD Stages. In A37. COPD COMORBIDITIES (p. A1460). American Thoracic Society.

[30]. Bode, F. R., Dosman, J. A. M. E. S., Martin, R. R., Ghezzo, H. E. B. E. R. T. O., \& Macklem, P. T. (1976). Age and sex differences in lung elasticity, and in closing capacity in nonsmokers. Journal of applied physiology, 41(2), 129-135.

[31]. Schoenberg, J. B., Beck, G. J., \&Bouhuys, A. (1978). Growth and decay of pulmonary function in healthy blacks and whites. Respiration physiology, 33(3), 367-393.

[32]. Campbell, E. J. (2008). Aging of the respiratory system. Fishman 's Pulmonary Diseases and Disorders. 4th ed. China: Mcgraw Hill Companies, Inc, 263-76.

[33]. Saxena, Y., Saxena, V., Dvivedi, J., \& Sharma, R. K. (2008). Evaluation of dynamic function tests in normal obese individuals. Indian J PhysiolPharmacol, 52(4), 375-382.

[34]. Saint-Pierre, M., Ladha, J., Berton, D. C., Reimao, G., Castelli, G., Marillier, M., ... \&Neder, J. A. (2019). Is the slow vital capacity clinically useful to uncover airflow limitation in subjects with preserved FEV1/FVC ratio? Chest, 156(3), 497-506.

[35]. Dunn, A. L., Marcus, B. H., Kampert, J. B., Garcia, M. E., Kohl III, H. W., \& Blair, S. N. (1999). Comparison of lifestyle and structured interventions to increase physical activity and cardiorespiratory fitness: a randomized trial. Jama, 281(4), 327-334.

[36]. Bellemare, F., Jeanneret, A., \& Couture, J. (2003). Sex differences in thoracic dimensions and configuration. American journal of respiratory and critical care medicine, 168(3), 305-312.

[37]. Hutchinson, J., 1846. On the capacity of the lungs, and on the respiratory functions, with a view of establishing a precise and easy method of detecting disease by the spirometer. Med. Chir. Trans. 29, $137 \mathrm{e} 252$

[38]. Gilbert, R., Auchincloss Jr, J. H., \&Peppi, D. (1981). Relationship of rib cage and abdomen motion to diaphragm function during quiet breathing. Chest, 80(5), 607-612.

[39]. Ratnovsky, A., \&Elad, D. (2005). Anatomical model of the human trunk for analysis of respiratory muscles mechanics. Respiratory physiology \& neurobiology, 148(3), 245-262.

[40]. Jain, S. K., \& Gupta, C. K. (1967). Age, height and body weight as determinants of ventilatory'norms' in healthy men above forty years of age. The Indian journal of medical research, 55(6), 606.
[41]. Costa, D., Barbalho, M. C., Miguel, G. P. S., Forti, E. M. P., \& Azevedo, J. L. M. C. (2008). The impact of obesity on pulmonary function in adult women. Clinics, 63(6), 719-724.

[42]. Banerjee, J., Roy, A., Singhamahapatra, A., Dey, P. K., Ghosal, A., \& Das, A. (2014). Association of body mass index (BMI) with lung function parameters in non-asthmatics identified by spirometric protocols. Journal of clinical and diagnostic research: JCDR, $8(2), 12$.

[43]. Solanki, S., Mirdha, P., \& Choudhary, R. A comparative study of pulmonary function in healthy male and female subjects of western Rajasthan.

[44]. Colebatch, H. J., Greaves, I. A., \& Ng, C. K. (1979). Exponential analysis of elastic recoil and aging in healthy males and females. Journal of Applied Physiology, 47(4), 683-691.

[45]. Behera, A. A., Behera, B. K., Dash, S., \& Mishra, S. (2014). Effect of body mass index on gender difference in lung functions in Indian population. International Journal of Clinical and Experimental Physiology, 1(3), 229-231.

[46]. Thyagarajan, B., Jacobs, D. R., Apostol, G. G., Smith, L. J., Jensen, R. L., Crapo, R. O., ... \& Williams, O. D. (2008). Longitudinal association of body mass index with lung function: the CARDIA study. Respiratory research, 9(1), 31.

[47]. Park, J. E., Chung, J. H., Lee, K. H., \& Shin, K. C. (2012). The effect of body composition on pulmonary function. Tuberculosis and respiratory diseases, 72(5), 433-440.

[48]. Brooks LJ, Byard PJ, Helms RC, et al. Relationship between lung volume and tracheal area as assessed by acoustic reflection. J Appl Physiol 1988; 64: 10501054. 